\title{
Celiac Disease: Participation of Cytokines and Other Factors in the Immune Response
}

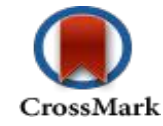

\author{
Tania Beatriz Romero- Adriàn ${ }^{1,2^{*}}$, Jorymar Leal-Montiel ${ }^{1,2}$, Gerardo Fernández $^{1}$ \\ ${ }^{1}$ Graduate Studies in Immunology, Faculty of Medicine, University of Zulia, Maracaibo, Venezuela \\ ${ }^{2}$ Institute of Biological Research, Faculty of Medicine, University of Zulia, Maracaibo, Venezuela
}

\begin{abstract}
*Corresponding Author: Tania Beatriz Romero- Adrian, Graduate Studies in Immunology, Institute of Biological Research, Faculty of Medicine, University of Zulia, 69 B Avenue, 77-49th Streets, Panamericano Sector, Maracaibo, Venezuela. Tel: +58-0261-7532659; Fax: +58-0261-7533822; E-mail: corporacionbiomedica.alt@gmail.com
\end{abstract}

Received Date: July 27, 2015

Accepted Date: November 19, 2015

Published Date: November 23, 2015

Citation: Romero- Adrian, T.B., et al. Celiac disease: Participation of cytokines and other factors in the immune response. (2015) J Gastrointest Disord Liver Func 1(1): 15- 23.

\begin{abstract}
Celiac disease (CD) is an autoimmune enteropathy that affects $1 \%$ of most populations. Genetic, immunological and environmental factors (the intake of gluten) participate in the establishment and development of the disease. Cells and cytokines make a network of interactions leading to intestinal inflammatory process. IFN- $\gamma$ is the most potent inducer of transglutaminasa 2 (TG2) expressions, acts synergistically with TNF- $\alpha$, and triggers the upregulation of HLA expression, the secretion of tissue-damaging Metalloproteinases (MMPs) from fibroblasts, the heightened cytotoxicity of Intraepithelial Lymphocytes (IELs) against enterocytes with increased apoptosis and villous flattening. IL-12 and IL-18 have an important suppressive effect on the induction of antigen-specific tolerance and provoke a more vigorous response on challenge. Upregulation of IL-15 expression by epithelial cells and Dendritic Cells (DCs) in the lamina propria seems to contribute to alter signalling properties of the CD8+ intraepithelial lymphocytes and provokes the resistance of human T cells to the suppression by regulatory T cells. IL-15 and IL-21 might also act in concert to disrupt local mechanisms of immune tolerance. Increased expressions of several Th17 related cytokines in patients with active $\mathrm{CD}$ have been demonstrated. IL-10 acts by interfering with antigen presentation and induces hyporesponsive in gliadin specific T cells. TGF- $\beta 1$ expression increased have been observed in the lamina propria of children with intestinal villous atrophy, which appoint its importance in the pathogenesis of $\mathrm{CD}$. In this disease appreciated alteration of immune regulation with predominance of the Th1 and Th17 phenotype cytokines. The profile of mucosal effector cytokines differs between refractory CD and active $\mathrm{CD}$; however, maintain and worsen the inflammatory process. Immune dysregulation, loss of tolerance, increase of pro-inflammatory cytokines and non-suppression of the inflammatory response despite the presence of counter-regulatory mechanisms constitute relevant events in $\mathrm{CD}$.
\end{abstract}

Keywords: Celiac disease; Cytokines; Response immune

\section{Introduction}

Celiac Disease (CD) or gluten-sensitive enteropathy affects $1 \%$ of most populations and is traditionally regarded as a childhood disease; however, researchers reveal high incidence and prevalence in adulthood ${ }^{[1]}$. This disease is considered more prevalent in women due to increased use of health services when compared with men ${ }^{[2]}$. HLA-linked genes are relevant to CD. HLA haplotypes, DQ2/DQ8, are more frequent in female than in male CD patients ${ }^{[3]}$. HLA-DQ2.5 (DQA1*05, DQB1*02) is expressed about $90 \%$ of CD patients whereas most of the remaining patients express HLA-DQ8 (DQA1*03, DQB1*03:02) or HLA-DQ2.2 $(\mathrm{A} 1 * 02: 01 \text {, DQB } 1 * 02: 02)^{[4]}$. In DQ2 negative patients, the IL6 -174GG genotype (homozygous) may be an additional risk marker for $\mathrm{CD}$, represented a susceptibility factor for the disease when TNF-308A is negative ${ }^{[5]}$. The genetic differences present worldwide

Copyrights: (C) 2015 Romero- Adrian, T.B. This is an Open access article distributed under the terms of Creative Commons Attribution 4.0 International License. 
are not fully understood ${ }^{[6]}$. Researchers have report an increased prevalence of CD among First-Degree Relatives (FDRs) of celiac patients ${ }^{[7,8]}$.

European Society of Pediatric Gastroenterology, Hepatology and Nutrition Criteria (ESPGHAN) distinguish three different forms of CD: latent or potential form, the silent form (asymptomatic) and the symptomatic form. The first form is defined by the presence of anti-celiac antibodies, the second by the presence of anti-celiac antibodies and villous atrophy of the small intestine and the third by the presence of anti-celiac antibodies, villous atrophy and clinical symptoms ${ }^{[9]}$.

Predisposition to celiac disease is believed to depend on multiple genetic, immunological and environmental factors (the intake of gluten ${ }^{[10]}$ (Figure 1). The genetic condition and abnormal immune response to dietary gluten is crucial for the development of $\mathrm{CD}$. The main source of gluten comes from cereals, especially wheat. Represents $80 \%$ of wheat proteins and is composed of gliadin and glutenin. Authors have demonstrated the existence of immunogenic and toxic gliadin peptides ${ }^{[11-14]}$. Investigation indicates that $\alpha$-gliadin (57-73), $\gamma$-gliadin (139-153) and $\omega$-gliadin (102-118) are the most active gluten peptides in DQ2+ celiac patients ${ }^{[15]}$. CD is an autoimmune enteropathy that results of a type IV hypersensitivity reaction mediated by antigen-specific effector $\mathrm{T}$ cells. This reaction takes some time to develop and gliadin antigen is absorbed by the gut and triggers the response. This type of immune reaction causes villous atrophy in small bowel and malabsorption ${ }^{[16-18]}$.

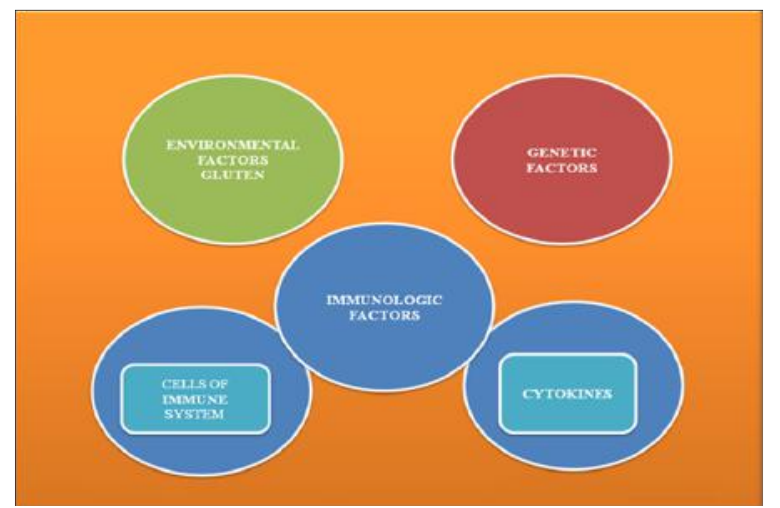

Figure 1: Factors Involved in the Establishment and Development of Celiac Disease

The "celiac iceberg" comprising potential or latent, silent and symptomatic celiac disease. In the first form the mucosa is normal; in the last two the mucus is injured ${ }^{[19]}$. CD can present with gastrointestinal or extraintestinal manifestations (e.g., malabsorption or Duhring's dermatitis herpetiformis) $)^{[20]}$. Undiagnosed CD patients cannot receive opportune treatment, and will have a probability elevated for developing of malignant diseases and secondary autoimmune disorders ${ }^{[19]}$. However, the small intestinal inflammation observed in CD regresses after elimination of gluten-containing foods, leading to the recovery of the structure and function of the mucosa which reveal the harmful effects of the gliadin in susceptible patients and the importance of a diet free of gluten ${ }^{[20]}$.

Life-threatening complications, although relatively rare, can include the development of Refractory CD (RCD) and Enteropathy-Associated T cell Lymphomas (EATLs) ${ }^{[16-18]}$. RCD has been subdivided into two subgroups according to the normal
(Type I or RCD I) or abnormal (Type II or RCD II) phenotype of intraepithelial lymphocytes. RCD II is considered as a low-grade intraepithelial lymphoma and has a very poor prognosis ${ }^{[21]}$.

Investigators had demonstrated that the Iron-deficiency anemia is a common extraintestinal manifestation of celiac disease. In these patients with positive celiac disease serology the biopsy should be recommended ${ }^{[22]}$. The CD has been linked to: type 1 diabetes ${ }^{[23]}$, sepsis ${ }^{[24]}$, Systemic Lupus Erythematosus $(\mathrm{SLE})^{[25]}$ among others ${ }^{[26-28]}$. Authors appoint that skin diseases associated with CD can be classified into: proved association, Improvement in skin disease by gluten free-diet or/and presence of serologic markers in several data and Fortuitous association $^{[29]}$.

Over time and due to the global problems of $\mathrm{CD}$, researchers have developed various ways to avoid the adverse effects of gliadin, such as: genetically modified wheat cultivars, transamidated gliadins that revert the inflammatory phenotype by an anti-inflammatory in the gliadin-inducible immune response and a desensitizing vaccine (NexVax2) that have three dominant gluten peptides and induces tolerogenic response in CD patients ${ }^{[30,31]}$. Also, researchers have demonstrated that anti-wheat gliadin IgY antibody produced in their study has proved to inhibit absorption of gliadin and gliadin-induced inflammatory process in Caco 2 cell culture model of CD. Anti-gliadin IgY has a therapeutic potential to be used to treat $\mathrm{CD}^{[32]}$.

For many years, studies have been conducted involving the subset of $\mathrm{T}$ cells and cytokines in different physiological and pathological clinical entities ${ }^{[33-39]}$. In this review we will emphasize the importance of the immune response and the participation of cells, pro-inflammatory and anti-inflammatory cytokines in the small intestine in patients with $\mathrm{CD}$. We believe that regulating proteins form a network of events that amplify the damage the intestine and and they could be used as a therapeutic target for disease control.

\section{Cells, Cytokines and Other Factors Participating in the Im- mune Response}

Celiac disease results from innate and adaptive immune system dysregulation. Activation of the adaptive immune system implies that gliadin (the toxic component of gluten) cross the intestinal epithelium. It has been hypothesized that increased intestinal permeability is an early event in CD pathogenesis ${ }^{[40]}$. Natives Gluten peptides are deaminated by enzyme tissue Transglutaminase (tTG) and bind HLA-DQ2 and HLA-DQ8 molecules. Deamidated gluten proteins have enhanced affinity for the HLA-DQ heterodimer of antigen-presenting cells. These cells activate helper $\mathrm{T}$ cells and produce a T-helper type 1 response in the mucosa of celiac patients. It is triggered an inflammatory reaction with activation of macrophages, cytotoxic $\mathrm{T}$ cells and plasma cells among other cells. Proinflammatory cytokines secreted by different cellular types are involved in the amplification of the immune response and involvement of the small intestine. These events cause disruption of the mucosa, matrix remodeling, cell death, the secretion of anti-gliadin and anti-tTG antibodies ${ }^{[41]}$ (Figure 2). Researches appoint that some gluten peptides efficiently elicit inflammatory T-cell responses whereas others do not. The explanation could be: (a) resistance to proteolytic degradation, (b) substrate affinity to TG2 (c) specificity to bind HLA molecules ${ }^{[42]}$. 


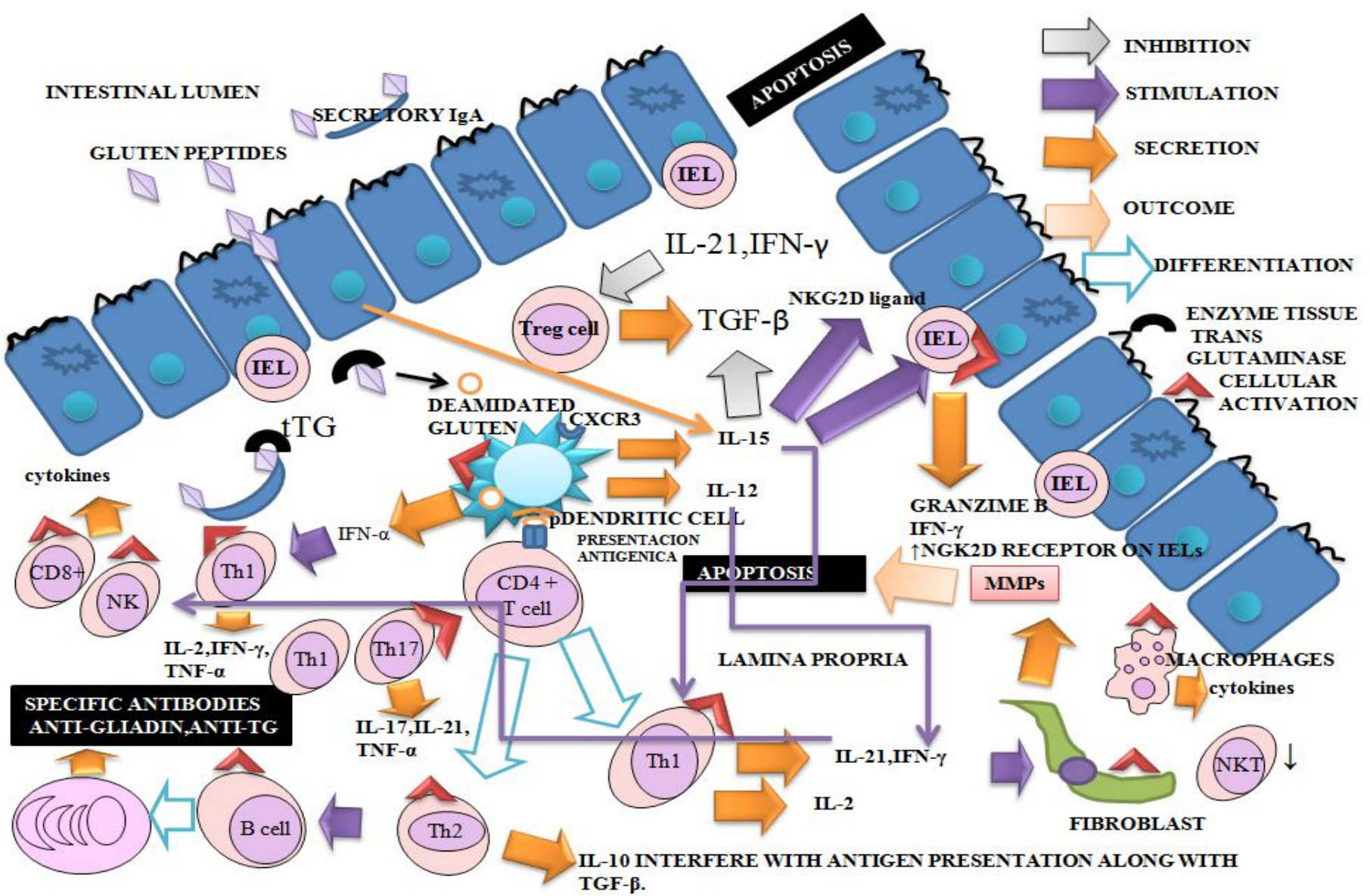

Figure 2: Network of Cytokines in CD: Enterocytes and Lamina Propria of Small Intestine

- Natives gluten peptides are deaminated by enzyme tissue Transglutaminase (tTG) and bind HLA-DQ2 and HLA-DQ8 molecules. Antigen-presenting cells activate helper $\mathrm{T}$ cells and trigger an inflammatory reaction with activation of macrophages, cytotoxic $\mathrm{T}$ cells and plasma cells among others . Proinflammatory cytokines secreted by different cellular types are involved in the amplification of the immune response and involvement of the small intestine. These events cause disruption of the mucosa, matrix remodeling, cell death and the secretion of anti-gliadin and anti- tTG antibodies.

- Th1 cells are abundant in the lamina propria and responsible for the maintenance of a suitable environment for antibody production at the duodenal mucosa and for the cytotoxic activity of IELs in untreated CD patients. Increased numbers of TCR $\gamma \delta+$ IELs have also been observed in the small intestinal mucosa of CD patients. A pA2 gliadin peptide activates mucosa infiltrating CD8+ $\mathrm{T}$ cells in the context of HLA class I restriction, suggesting a role for these cells in CD epithelial cell death.

- NKT cells immunoregulatory deficiency may play an important role in loss of immunological tolerance. The suppressor activity of Tregs is significantly impaired in CD. A defect in Tregs function could play a role in the pathogenesis of CD and in CD-associated autoimmunity. Regulatory properties of these cells are influenced through the signals received from the tissue environment.

- The increase of IL-2 and sIL-2R levels suggests indirectly T-cell activation. IFN- $\gamma$ is upregulated in the mucosa of untreated CD patients and returns to normal levels after gluten is withdrawn from the diet.

- Elevated levels of IL-12 and IL-18 have an important suppressive effect on the induction of antigen-specific tolerance. IL-15 augments the production of granzyme b by IELs and IFN- $\gamma$ by IELs and Th1 cells; enhances the expression of the activating NGK2D receptor on IELs; induces the NKG2D ligand, MHC class I chain related ligand A (MICA), on epithelial cells. IL-15 plays a crucial role in the maturation and activation of dendritic cells and macrophages.

- Increased expression of several Th17-related cytokines have been demonstrated in patients with active CD. IL-10 acts by interfering with antigen presentation and provokes the induction of hyporesponsive in gliadin specific T cells. TGF- $\beta$ is inhibited by IL-15. This effect might promote and keep the intestinal inflammation in CD. Three important chemokines, CXCL9 (Mig), CXCL10 (IP-10) and CXCL11 (I-TAC), bind to different domains of CXCR3 and differentially activate the receptor, each inducing distinct biological effects on receptor internalization and the chemotaxis. - The incremented production of immunomodulatory cytokines might be due to an inefficient attempt of regulating the mucosal inflammation. Synergistic, antagonistic, redundant and pleiotropic biological effects of the cytokines can modify immuno-pathological consequences.

- $\mathrm{CD}$ is characterized by an impressive clinical heterogeneity, ranging from totally asymptomatic to fully symptomatic forms. Also, immunological events related to cytokines are complex because there are many participants and determinants factors. It considers that there are immuno histological differences among the patients related or not with the clinic.

- IEL, intraepithelial lymphocyte; LP, lamina propria; MMPs, metalloproteinases 


\section{Function of the Cells}

Many cells take place in the immune response in CD. Neutrophils and lymphocytes are the cells that play a major role in inflammatory processes. Neutrophil-to-Lymphocyte Ratio (NLR) was introduced as a useful index for diagnosis or prognosis of different diseases ${ }^{[43]}$. NLR might be used as a sensitive laboratory index in screening and diagnosis of $\mathrm{CD}^{[44]}$. The search for new methods of laboratory of high sensitivity and specificity is of great importance since it is estimated that up to $90 \%$ of patients are undiagnosed due to subclinical presentations ${ }^{[45]}$.

DCs as Antigen Presenting Cells (APCs) participate in the presentation of gliadin peptides to mucosal CD4+ $\mathrm{T}$ cells and they may promote the persistence of the inflammatory response by interacting with lamina propria T cells. Deregulation of DC function, either as a primary effect of gene mutations or as a consequence of defective integration with environmental cues, may result in intestinal disease ${ }^{[46]}$. Rapid accumulation of CD14+CD11c+ DCs is specific to CD and precedes changes in mucosal architecture, indicating that this DC subset may be directly involved in the immunopathology of the disease ${ }^{[47]}$. Others appoint a significant reduction of the absolute number of DC, mainly the plasmacytoid subset, both in untreated and treated CD patients ${ }^{[48]}$. Distinct subpopulations of APCs in celiac disease may exert different functions in the pathogenesis ${ }^{[49]}$.

The CD4+ T cells play an important role in tissue injury ${ }^{[50]}$ and in lamina propria predominates the phenotype Th1 with production of cytokines in response to gluten stimulation $^{[51]}$. Researches ${ }^{[52]}$ showed that patients with CD may fail to regulate $\mathrm{T}$ cell response to gluten because of an impaired capacity for extra-thymic $\mathrm{T}$ cell receptor gene rearrangement. Th1 cells are abundant in the LP and responsible for the maintenance of a suitable environment for antibody production at the duodenal mucosa and for the cytotoxic activity of IELs in untreated CD patients ${ }^{[53]}$. Authors indicate that the profile of mucosal effector cytokines differs between RCD and ACD. They reported increase of IFN- $\gamma$, IL-17A and IL-21 transcript in ACD as well as increase of IL-6, TNF- $\alpha$ and IL-17A transcript in RCD. No significant increment in IL-15 transcripts was observed in both ACD and RCD, whereas IL-15 protein was increased in active $\mathrm{CD}^{[54]}$.

In humans and mice, $\mathrm{TCR} \gamma \delta^{+} \mathrm{T}$ cells are preferentially located in epithelia of various organs, and they constitute a substantial fraction of intestinal Intraepithelial Lymphocytes (IELs) ${ }^{[55,56]}$. It has been proposed that $\mathrm{TCR} \gamma \delta^{+} \mathrm{T}$ cells bridge innate and adaptive immune responses ${ }^{[57]}$. In the intestinal mucosa, these cells play a vital role in the maintenance of epithelial integrity and repair through the production of cytokines and growth factors ${ }^{[58-61]}$. Increased numbers of TCR $\gamma \delta^{+}$IELs have also been observed in the small intestinal mucosa of CD patients ${ }^{[22-65]}$. An increase of this IEL subset has been observed in all stages of disease: Latent CD (LCD) and Active CD (ACD) or those on a Gluten-Free Diet (GFD) and in some first-degree relatives of CD patients with HLA-DQ2 ${ }^{[66-68]}$.

Investigation provides evidence that human small intestinal CD8+TCR $\gamma \delta^{+}$IELs have attributes of Tregs in the context of CD. It found that $\mathrm{CD} 8-\mathrm{TCR} \gamma \delta^{+}$IELs, which are also increased in individuals on GFD, have suppressive capabilities, although these are much weaker than those of CD $8+\mathrm{TCR} \gamma \delta^{+} \mathrm{IELs}^{[69]}$. For others, a pronounced epithelial reaction in active $\mathrm{CD}$ with all three major activated IEL subsets, such as: $\gamma \delta^{+}$T cells, CD4+ $\alpha \beta$
$\mathrm{T}$ cells and CD8+ $\alpha \beta \mathrm{T}$ cells. Two groups are considered the largest producers of regulating proteins such as: CD4 $+\alpha \beta$ Tcells $(\mathrm{TNF}-\alpha)$ and CD $8+\alpha \beta$ Tcells (IFN- $\gamma$, IL-10, TNF- $\alpha$, TGF- $\beta)^{[70]}$.

Interaction of the activating NK cell receptors, NKG2D or the heterodimer CD94/NKG2C, expressed by CD8+TCR $\alpha \beta^{+}$ IELs, with their ligands MICA/B and HLA-E on enterocytes, respectively, results in the release of IFN- $\gamma$ and the contents of cytotoxic granules (perforin and granzyme B) that cause cytolysis of enterocytes ${ }^{[71-73]}$. With respect to invariant NK T cells, researchers have demonstrated that are systemically deficient and with defective cytokines production in $\mathrm{CD}$. These observations suggest that NK T cells immunoregulatory deficiency may play an important role in loss of immunological tolerance in $\mathrm{CD}^{[74]}$.

Regulatory $\mathrm{T}$ cells (Tregs) have an important role in CD. Recent studies show increased numbers of circulating and mucosal CD4+Foxp $3^{+}$cells in individuals with Active Celiac Disease (ACD), as compared to those on a GFD ${ }^{[75]}$. However, the suppressor activity of Tregs was significantly impaired in $\mathrm{CD}$ patients. These results suggest that a defect in Tregs function could play a role in the pathogenesis of CD and in CD-associated autoimmunity ${ }^{[76]}$.

When Th2 cells recognize antigen on B cells, helper T cells activate these cells to proliferate and differentiate into antibody- producing plasma cells. Investigators found that enzyme Transglutaminase 2 (TG2)-specific plasma cells were highly expanded in patients with active $\mathrm{CD}$, representing on average $10 \%$ of Antibody-Secreting Cells (ASCs) within the duodenal mucosa. These autoantibodies presented limited somatic hypermutation in intestinal lesions of the ill patients ${ }^{[77]}$.

Anti-TG2 antibodies are a key feature of CD. IgA anti-TG2 antibodies are useful for diagnostic purposes because they have sensitivity and specificity close to $100 \%{ }^{[78]}$. The autoantibodies that are commonly related to CD are IgA anti-tTG2 and the Anti-Endomysium (EMA). These last antibodies have been reported in some studies, to decline or disappear in association with a clinical and/or histological response to a gluten-free $\operatorname{diet}^{[9]}$. However, there are reports of patients with positive histology on duodenal biopsy samples but negativity of anti-TG2 antibodies. These patients have been diagnosed as Seronegative Celiac Disease (SNCD) ${ }^{[79]}$. Seronegative (EMA or tTG) CD occurs in less than $10 \%$ of celiacs, particularly in those with lesser degrees of villous atrophy ${ }^{[9]}$.

\section{Cytokines and their participation in the immune response}

Cell participation and secretion of regulatory proteins or cytokines establish a network of interactions leading to inflammatory consequences that could result in clinical manifestations. These regulating proteins have synergistic, antagonistic, redundant and pleiotropic biological effects that can affect the immune response in CD also occur in others diseases. There are cytokines pro-inflammatory and anti-inflammatory. These proteins can be regulated for the control of the immune system and the maintenance of homeostasis ${ }^{[37]}$.

In CD some cytokines more that others have been important mediators to amplified the immune response. Knowing the biological actions of cytokines, serum concentrations and their tissue expression could establish the inherent changes to this disease. Also, The balance between STAT-4/T-bet and STAT-6/GATA-3 thus seems to dictate the fate of T cell polarization during the immune response ${ }^{[80]}$. 


\section{Thymic Stromal Lymphopoietin (TSLP)}

This regulating protein is constitutively expressed by epithelial cells, is very important in the preservation of immune tolerance in the gut. Authors have demonstrated reduced mucosal TSLP expression may contribute to the upregulation of T-cell-derived cytokines and myofibroblast-released matrix-degrading enzymes. This deficiency may contribute to intestinal damage in refractory and untreated CD. Also, they appoint that is necessary to verify whether the therapeutic restoration of TSLP might be useful, especially in refractory patients with CD, who no longer respond to $\mathrm{GFD}^{[81]}$.

\section{Interleukin-2}

Interleukin-2 (IL-2) is produced by Th0, Th1 and some CTL. It stimulates growth of B, T and NK cells. The serum levels of IL-2, soluble IL-2 receptor (sIL-2R), and Antibodies Anti-Gliadin (AGA) were significantly increased in celiac patients. The increase of IL-2 and sIL-2R levels suggests indirectly T-cell activation in these patients ${ }^{[82]}$.

sIL-2R and IL-6 levels have a good correlation with $\mathrm{CD}$ activity and can be used as reliable markers for detecting minimal transgression from GFD $^{[83]}$. Serum sIL-2R levels in patients with celiac disease reflect specific immunological activation in response to gluten ingestion. Measurement of serum sIL-2R may therefore be useful in the assessment of response to treatment in patients with celiac disease ${ }^{[84]}$.

\section{Interleukin-6}

Interleukin-6 (IL-6) is secreted by Th2 cells, B cells, monocytes, macrophages, endothelial, epithelial, fibroblast cells. It is an important inductor of the acute-phase response. IL6 , together with other cytokines as IL- 1 and $\mathrm{TNF}-\alpha$, has effect on hepatocytes, Bone-marrow, endothelium, hypothalamus, fat, muscles and $\mathrm{DCs}^{[85]}$.

Researches had demonstrated that DQ2 negative CD patients show an increased frequency of genotypes associated to IL6 high production ${ }^{[5]}$. The functional-174G/C IL6 polymorphism seems to influence CD susceptibility in girls ${ }^{[86]}$. Authors ${ }^{[54]}$ had observed a significant increment of IL-6 in RCD but no in ACD. The mechanisms of this difference are not fully understood.

\section{Interferon- $\gamma$ and Tumoral Necrosis Factor-o}

IFN- $\gamma$ is a proinflammatory cytokine secreted by Th1, CTL, NK cells. Study revealed that the numbers of IFN- $\gamma$-producing cells in the peripheral blood was increased significantly in children with untreated CD and after gluten challenge compared with healthy controls ${ }^{[87]}$.

Neutralization of IFN- $\gamma$ has been shown to prevent "gluten"-induced mucosal damage, at least in biopsies of CD mucosa maintained in organ culture ${ }^{[8]}$. The transcription factor T-bet, which directs Th1 cell-lineage (secretor of IFN- $\gamma$ ), is upregulated in the mucosa of untreated $C D$ patients and returns to normal levels after gluten is withdrawn from the diet ${ }^{[80]}$.

IFN- $\gamma$ triggers the upregulation of HLA expression facilitating $\mathrm{T}$ cell priming and expansion, the secretion of tissue-damaging Metalloproteinases (MMPs) from fibroblasts, the heightened cytotoxicity of IELs against enterocytes with increased enterocyte apoptosis and villous flattening. CD4+ gliadin-reactive cells can differentiate into Th1, Th17, Tr1 and Foxp
3 phenotypes in the presence of cytokines as IFN- $\gamma$, TGF- $\beta^{+}$IL- 6 , IL-10 and TGF- $\beta^{+}$IL- 2 respectively ${ }^{[89]}$. The surrounding environment and other factors set the appropriate way.

TNF- $\alpha$ is cytokine produced by Th1, some Th2 and some CTL phenotypes. It induces nitric oxide production and activates microvascular endothelium among other biological actions. Researchers found that TNF- $\alpha$ acts synergistically with IFN- $\gamma$ which is the most potent inducer of TG2 expression ${ }^{[00]}$. TG2 plays a critical role in the pathogenesis of celiac disease (CD), because it is able to deamidate glutamine residues present in toxic proteins from wheat and related cereals ${ }^{[91]}$.

Probiotic intervention with Bifidobacterium breve strains has shown a positive effect on decreasing the production of pro-inflammatory cytokine (TNF- $\alpha)$ in child with $C D$ on GFD. Gut microbiota dysbiosis play an important role in the pathogenesis of CD. Dysbiosis may contribute to disrupting the immune homeostasis and gut integrity, promoting CD onset and aggravating the pathological process ${ }^{[92]}$.

\section{Interleukin-12}

IL-12 is produced by antigen-presenting cells such as $\mathrm{B}$, macrophages and DCs. It permits the differentiation of $\mathrm{CD}+\mathrm{T}$ cells into Th1 but suppresses $\mathrm{Th} 2^{[93]}$. Authors have demonstrated that IL-12p70 were elevated significantly in children with celiac disease compared to controls. A prolonged systemic inflammation may contribute to long-term with complications in untreated celiac disease. After gluten-free diet, levels of IL-12 decreased significantly ${ }^{[94]}$.

Elevated levels of IL-12 and IL-18 have an important suppressive effect on the induction of antigen-specific tolerance and provoke a more vigorous response on challenge. By their biological actions augment IFN- $\gamma$ production, as well as increasing activation of antigen-presenting dendritic cells ${ }^{[95]}$.

\section{Interleukin-15 and interleukin-21}

IL-15 is a cytokine synthesized by mononuclear phagocytes and other cells. It has important functions for growth promotion and survival for T, NK cells and provides activating and survival signals to $\mathrm{CTL}$ and is thought to indirectly modulate CD4+ T cell responses by acting on APC ${ }^{[96,97]}$.

In $\mathrm{CD}$ upregulation of IL-15 expression by epithelial cells and DCs in the lamina propria seems to contribute to alter signaling properties of the CD8+ intraepithelial lymphocytes population. Also, induces increased expression of ligands on intestinal epithelial cells [for example, Major Histocompatibility Complex (MHC) class I chain-related protein (MIC)] that are targets of the cytotoxic, TCR-independent NK-like cells. IL-15 produced by DCs in the CD mucosa also might be important in the adaptive T cell response to "gluten." ${ }^{\text {"[71,98] }}$. Another study also has shown increased levels of IL-15 in the intestinal epithelium and lamina propria of patients with untreated CD compared to patients in remission and healthy controls ${ }^{[99]}$. It has been shown that IL-15 can synergize with IL-21, a cytokine produced by CD4+ T, NK T cells as well as by human intestinal CD3+ Lamina Propria T Lymphocytes (LPLs), that stimulates IFN- $\gamma$ production and cytolytic activity of CD8+ T cells and NK cells ${ }^{[100]}$.

The critical role of IL-15 in intestinal epithelial cell death is induced by NKG2D (activating NK receptors)-expressing IELs. IL-15 and IL-21 might also act in concert to disrupt local mechanisms of immune tolerance. These cytokines seem to 
differentially modulate some aspects of both innate and adaptive immunity, such as dendritic cell maturation and $\mathrm{T}$ cell apoptosis At least in some stages of the inflammatory process, IL-15 and IL-21 can exert opposing effects on the gluten-driven immune response $^{[101,102]}$.

IL-15 augments the production of granzyme B by IELs and IFN- $\gamma$ by IELs and Th1 cells; enhances the expression of the activating NGK2D receptor on IELs; induces the NKG2D ligand, MHC class I chain related ligand A (MICA), on epithelial cells $^{[103]}$. IL-15 is overexpressed in the intestine of patients with $\mathrm{CD}$, but does not impair the generation of functional Tregs but renders human T cells are resistant to Treg suppression ${ }^{[104]}$.

Interleukin 15 (IL15) contributes to the pathogenesis of celiac disease. In mice given food antigen, cooperation between IL15 and CD4+ T cells is necessary and sufficient to activate CD8+ $T$ cells and damage the small intestine ${ }^{[105]}$. IL-15 sensitivity may provide attractive new targets for the treatment and/ or prevention of this disease and potentially other autoimmune disorders $^{[106]}$

\section{Interleukin-17}

IL-17, a cytokine pro-inflammatory, is secreted by Th 17 cells. Th17 cells cytokines are involved in several autoimmune or inflammatory diseases ${ }^{[107]}$. Authors ${ }^{[108]}$ implicated the Th17 immune response in CD pathogenesis, evidenced by the increased expression of several Th17-related cytokines in patients with active CD. Despite of the presence of an endogenous counter-regulatory mechanism in the intestinal mucosa of celiac patients, the inflammatory response is not suppressed. For some the role of Th17 phenotype in CD pathogenesis is ambiguous ${ }^{[89]}$. For others, predominate in both RCD and ACD and the secreted cytokines by that phenotype start and amplified the inflammatory process ${ }^{[54]}$. Further studies are necessary to clarify the potential of Th17 cells as therapeutic.

\section{Interleukin-18}

IL-18, a pro-inflammatory member of the IL-1 family, has been associated with autoimmunity and allergic disease. IL18 has been implicated in the loss of oral tolerance to mucosal antigens in many inflammatory disorders. This regulating protein in combination with IL-12 may be able to prevent the induction of oral tolerance to ovalbumin (OVA) in BALB/c mice. The possible mechanisms involved could be: effects on antigen-presenting dendritic cells, antigen-responding lymphocytes and/or the surrounding tissues. This defect in immunological tolerance is often observed in inflammatory disorders of the gut such as CD among others. The CD80 co-stimulatory molecule on dendritic cells was also increased by this combination of cytokines. This demonstrates that tolerance to mucosal antigens may be broken in vivo ${ }^{[95]}$.

\section{Interleukin-10}

IL-10 is a cytokine immunosuppressive produced by Th0, Th1 and Th2 lymphocytes, TCD8+ cells, monocytes, keratinocytes and activated B cells. The production of IL-10 (along with IFN- $\gamma$ ) in the duodenum during ACD has been reported elsewhere ${ }^{[70]}$, indicating that the post-challenge IL-10 production may be part of a normal celiac response.

IL-10 secreting, type 1 regulatory (TR1) CD4+T clones were described in the LP of CD patients on a GFD. These T cells were gliadin specific and could suppress the proliferation of pathogenic CD4+ Th0 cells ${ }^{[109]}$.

Data provide the first evidence for an immunoregulatory effect of IL-10 on gliadin dependent $\mathrm{T}$ cell activation in treated and untreated CD mucosa. IL-10 acts by interfering with antigen presentation and provokes the induction of hyporesponsive in gliadin specific T cells ${ }^{[110]}$.

\section{Transforming Growth Factor- $\beta$}

TGF- $\beta$ modulates the functions of T lymphocytes and macrophages $^{[93]}$. This cytokine have an effect inhibitor of Th1 lymphocytes. TGF- $\beta$ is inhibited by IL-15. This effect might promote and keep the intestinal inflammation in celiac disease. IL-15 is good therapeutic target in inflammatory diseases.

Researchers have shown that the Transforming Growth Factor- $\beta 1$ (TGF- $\beta 1$ ) expression was increased in the lamina propria of children with intestinal villous atrophy, which appoint its importance in the pathogenesis of CD. TGF- $\beta 1$ is obligatory for the generation of both Treg and Th17 cells with additional cytokines as IL-6 and IL-2 $1^{[12]}$.

Other reports appoint that the percentage of samples expressing TGF- $\beta$ mRNA from ACD patients was higher than from controls. The same happened with IL-2, (IFN)- $\gamma$, TNF- $\beta$, IL-10, IL-1 $\beta$, TNF- $\alpha$. Cytokine levels may to be relevant markers of disease activity ${ }^{[113]}$.

\section{Chemokines}

Chemokines belong to a large family of proteins called chemotactic cytokines. They can mediate the constitutive recruitment of leukocytes from the blood into tissues ${ }^{[14]}$.

Three chemokines, CXCL9 (Mig), CXCL10 (IP-10) and CXCL11 (I-TAC), bind to different domains of CXCR3 and differentially activate the receptor each inducing distinct biological effects on receptor internalization and chemotaxis ${ }^{[115]}$. Besides in the intestinal epithelium, CXCR3 is expressed on immune system cells, such as: activated $\mathrm{T}$ cells ${ }^{[116]}, \gamma \delta \mathrm{T}$ cells ${ }^{[117]}$, eosinophils ${ }^{[118]}$, B cells ${ }^{[119]}$, plasma cells ${ }^{[120]}$ and plasmacytoid dendritic cells ${ }^{[121]}$. CXCR3 is expressed more abundantly at the intestinal epithelium and lamina propria in patients with $\mathrm{CD}$ than in non-CD individuals ${ }^{[122]}$. A study reported that the chemokine receptor CXCR3 serves as a receptor for specific gliadin peptides that cause zonulin release and subsequent increase in intestinal permeability. The authors ${ }^{[123]}$ appoint that gliadin-induced IL-8(CXCL8) production was CXCR3-dependent gliadin only in $\mathrm{CD}$. This chemokine is a potent neutrophil-activating and chemoattractant and phagocytes cells as neutrophils are involved in the early immunological changes following gliadin exposure ${ }^{[124]}$. This indicates that the stimulus of the immune system caused by gluten peptides in susceptible patients, before and after antigen processing and subsequent presentation to T lymphocytes mobilize many cells to the lamina propria to archive the amplification and exacerbation of the response established important pathological consequences.

To conclude, in $\mathrm{CD}$ should take into consideration the following events: immune dysregulation, loss of tolerance, increased pro-inflammatory cytokines and non- suppression of the inflammatory response despite the presence of counter-regulatory mechanisms in the intestinal mucosa of celiac patients. In another order of ideas and for reflection, the existence of classifications as Marsh, Oberhuber and others to describe the types of 
intestinal lesions complicate the assessment of immunological events that take place in situ in patients with $\mathrm{CD}^{[125-127]}$.

Acknowledgement: This work was supported by Institute of Biological Research, Faculty of Medicine, University of Zulia.

Conflict of interest: The authors declare no conflict of interest

\section{References}

1. Vilppula, A., Kaukinen, K., Luostarinen, L., et al. Increasing prevalence and high incidence of celiac disease in elderly people: a population-based study. (2009) BMC Gastroenterol 9: 49.

2. Pinkhasov, R.M., Wong, J., Kashanian, J., et al. Are men shortchanged on health? Perspective on health care utilization and health risk behavior in men and women in the United States. (2010) Int J Clin Pract 64(4): 475-487.

3. Megiorni, F., Mora, B., Bonamico, M., et al. HLA-DQ and susceptibility to celiac disease: evidence for gender differences and parent-of-origin effects. (2008) Am J Gastroenterol 103(4): 997-1003.

4. Sollid, L.M., Lie, B.A. Celiac disease genetics: current concepts and practical applications. (2005) Clin Gastroenterol Hepatol 3(9): 843-851. 5. Garrote, J.A., Arranz, E., Gómez-González, E., et al. IL6, IL10 and TGFB1 gene polymorphisms in coeliac disease: differences between DQ2 positive and negative patients. (2005) Allergol Immunopathol 33(5): 245-249.

6. Araya, M., Oyarzun, A., Lucero, Y., et al. DQ2, DQ7 and DQ8 Distribution and Clinical Manifestations in Celiac Cases and Their First-Degree Relatives. (2015) Nutrients 7(6): 4955-4965.

7. Uenishi, R.H., Gandolfi, L., Almeida, L.M., et al. Screening for celiac disease in 1st degree relatives: A 10-year follow-up study. (2014) BMC Gastroenterol 14: 36 .

8. Vitoria, J.C., Arrieta, A., Astigarraga, I., et al. Use of serological markers as a screening test in family members of patients with celiac disease. (1994) J Pediatr Gastroenterol Nutr 19(3): 304-309.

9. Freeman, H.J., Chopra, A., Clandinin, M.T., et al. Recent advances in celiac disease. (2011) World J Gastroenterol 17(18): 2259-2272.

10. Guandalini, S., Setty, M. Celiac disease. (2008) Curr Opin Gastroenterol 24(6): 707-712.

11. Gianfrani, C., Troncone, R., Mugione, P., et al. Celiac disease association with $\mathrm{CD} 8+\mathrm{T}$ cell responses: identification of a novel gliadin-derived HLA-DQ2-restricted epitope. (2003) J Immunol 170(5): 2719-2726.

12. Sturgess, R., Day, P., Ellis, H.J., et al. Wheat peptide challenge in coeliac disease. (1994) Lancet 343(8900): 758-761.

13. Maiuri, L., Troncone, R., Mayer, M., et al. In vitro activities of A-gliadin-related synthetic peptides: damaging effect on the atrophic coeliac mucosa and activation of mucosal immune response in the treated coeliac mucosa. (1996) Scand J Gastroenterol 31(3): 247-253.

14. Martucci, S., Fraser, J.S., Biagi, F., et al. Characterizing one of the DQ2 candidate epitopes in coeliac disease: A-gliadin 51-70 toxicity assessed using an organ culture system. (2003) Eur J Gastroenterol Hepatol 15(12): 1293-1298.

15. Camarca, A., Anderson, R.P., Mamone, G., et al. Intestinal T Cell Responses to Gluten Peptides Are Largely Heterogeneous: Implications for a Peptide-Based Therapy in Celiac Disease. (2009) J Immunol 182(7): 4158-4166.

16. Patey-Mariaud De Serre, N., Cellier, C., Jabri, B., et al. Distinction between coeliac disease and refractory sprue: a simple immunohistochemical method. (2000) Histopathology 37(1): 70-77.

17. Cellier, C., Delabesse, E., Helmer, C., et al. Refractory sprue, coeliac disease, and enteropathy-associated T-cell lymphoma. French Coeliac Disease Study Group. (2000) Lancet 356(9225): 203-208.

18. Catassi, C., Bearzi, I., Holmes, G.K., et al. Association of celiac disease and intestinal lymphomas and other cancers. (2005) Gastroenterology 128 (4 Suppl 1): S79-S86.
19. Yuan, J., Gao, J., Li, X., et al. The tip of the "celiac iceberg" in China: a systematic review and meta-analysis. (2013) PLoS One 8(12): e81151.

20. Schuppan, D., Zimmer, K.P. The diagnosis and treatment of celiac disease. (2013) Dtsch Arztebl Int 110(49): 835-846.

21. Kelly, C.P., Bai, J.C., Liu, E., et al. Advances in diagnosis and management of celiac disease. (2015) Gastroenterology 148(6): 1175-1186. 22. Ertekin, V., Tozun, M.S., Küçük, N. The prevalence of celiac disease in children with iron-deficiency anemia. (2013) Turk J Gastroenterol 24(4): 334-338.

23. Bao, F., Yu, L., Babu, S., et al. One third of HLA DQ2 homozygous patients with type 1 diabetes express celiac disease-associated transglutaminase autoantibodies. (1999) J Autoimmun 13(1): 143-148.

24. Ludvigsson, J.F., Olen, O., Bell, M., et al. Coeliac disease and risk of sepsis. (2008) Gut 57(8):1074-1080.

25. Ludvigsson, J.F., Rubio-Tapia, A., et al. Increased risk of systemic lupus erythematosus in 29,000 patients with biopsy-verified celiac disease. (2012) J Rheumatol 39(10):1964-1970.

26. Koning, F. Pathophysiology of celiac disease. (2014) J Pediatr Gastroenterol Nutr 59 (Suppl 1): S1-S4.

27. Tanpowpong, P., Camargo, C.A. Early-life vitamin D deficiency and childhood-onset coeliac disease. (2014) Public Health Nutr 17(4): 823826.

28. Radlović, N. Celiac disease. (2013) Srp Arh Celok Lek 141(12):122-126.

29. Caproni, M., Bonciolini, V., D'Errico, A., et al. Celiac disease and dermatologic manifestations: many skin clue to unfold gluten-sensitive enteropathy. (2012) Gastroenterol Res Pract 2012(1): 952753.

30. Levy, J., Bernstein, L., Silber, N. Celiac disease: an immune dysregulation syndrome. (2014) Curr Probl Pediatr Adolesc Health Care 44(11): 324-327.

31. Rossi, M. Vaccination and other antigen-specific immunomodulatory strategies in celiac disease. (2015) Dig Dis 33(2): 282-289.

32. Gujral, N., Won Suh, J., Sunwoo, H.H. Effect of anti-gliadin IgY antibody on epithelial intestinal integrity and inflammatory response induced by gliadin. (2015) BMC Immunology 16: 41.

33. Leal, J.Y., Romero, T., Ortega, P., et al. Serum values of interleukin-10, gamma-interferon and vitamin A in female adolescents. (2007) Invest Clin 48(3): 317-326.

34. Monsalve-Castillo, F., Romero, T.A., Estévez, J., et al. Concentrations of cytokines, soluble interleukin-2 receptor, and soluble CD30 in sera of patients with hepatitis $B$ virus infection during acute and convalescent phases. (2002) Clin Diagn Lab Immunol 9(6): 1372-1375.

35. Monsalve, F., Romero, T., Estevez, J., et al. Serum levels of soluble CD30 molecule in hepatitis B virus infection. (2001) Rev Med Chil 129(11): 1248-1252.

36. Romero-Adrián, T.B., Ruiz, A., Molina-Vílchez, R., et al. Interleukin-2 receptor serum concentrations in normal pregnancy and pre-eclampsia. (2002) Invest Clin 43(2): 73-78.

37. Romero-Adrián, T.B., Leal-Montiel, J., Monsalve-Castillo, F., et al. Helicobacter pylori: bacterial factors and the role of cytokines in the immune response. (2010) Curr Microbiol 60(2): 143-155.

38. Romero-Adriàn, T.B., Leal- Montiel, J., Fernandez, G., et al. Role of cytokines and other factors involved in the Mycobacterium tuberculosis infection. (2015) World J Immunol 5(1): 16-50.

39. Romero- Adriàn, T.B., Leal- Montiel, J. Helicobacter pylori infection: Regulatory T cells and their participation in the immune response. (2013) Jundishapur J Microbiol 6(4): e5183.

40. Rubio-Tapia, A., Murray, J.A. Celiac Disease. (2010) Curr Opin Gastroenterol 26(2): 116-122.

41. Shah, S., Leffler, D. Celiac disease: an underappreciated issue in women's health. (2010) Womens Health (Lond Engl) 6(5): 753-766.

42. du Pré, M.F., Sollid, L.M. T-cell and B-cell immunity in celiac disease. (2015) Best Pract Res Clin Gastroenterol 29(3): 413-423.

43. Motomura, T., Shirabe, K., Mano, Y., et al. Neutrophil-lymphocyte ratio reflects hepatocellular carcinoma recurrence after liver transplantation via inflammatory microenvironment. (2013) J Hepatol 58(1): 58- 
64.

44. Sarikaya, M., Dogan, Z., Ergul, B., et al. Neutrophil-to-lymphocyte ratio as a sensitive marker in diagnosis of celiac disease. (2014) Ann Gastroenterol 27(4): 431-432.

45. Lohi, S., Mustalahti, K., Kaukinen, K., et al. Increasing prevalence of coeliac disease over time. (2007) Aliment Pharmacol Ther 26(9): 1217-1225.

46. Rescigno, M., Di Sabatino, A. Dendritic cells in intestinal homeostasis and disease. (2009) J Clin Invest 119(9): 2441-2450.

47. Beitnes, A.C., Ráki, M., Brottveit, M., et al. Rapid accumulation of $\mathrm{CD} 14+\mathrm{CD} 11 \mathrm{c}+$ dendritic cells in gut mucosa of celiac disease after in vivo gluten challenge. (2012) PLoS One 7(3): e33556.

48. Ciccocioppo, R., Ricci, G., Rovati, B., et al. Reduced number and function of peripheral dendritic cells in coeliac disease. (2007) Clin Exp Immunol 149(3): 487-496.

49. Beitnes, A.C., Ráki, M., Lundin, K.E., et al. Density of CD163+ $\mathrm{CD} 11 \mathrm{c}+$ dendritic cells increases and $\mathrm{CD} 103+$ dendritic cells decreases in the coeliac lesion. (2011) Scand J Immunol 74(2): 186-194.

50. MacDonald, T.T., Bajaj-Elliott, M., Pender, S.L. T cells orchestrate intestinal mucosal shape and integrity. (1999) Immunol Today 20(11): 505-510.

51. Nilsen, E.M., Jahnsen, F.L., Lundin, K.E., et al. Gluten induces an intestinal cytokine response strongly dominated by interferon gamma in patients with celiac disease. (1998) Gastroenterology 115(3): 551-563. 52. Bas, A., Forsberg, G., Sjoberg, V., et al. Aberrant extrathymic T cell receptor gene rearrangement in the small intestinal mucosa: a risk factor for coeliac disease? (2009) Gut 58(2): 189-195.

53. Jabri, B., Sollid, L.M. Tissue-mediated control of immunopathology in coeliac disease. (2009) Nat Rev Immunol 9(12): 858-870.

54. Caruso, R., Marafini, I., Sedda, S., et al. Analysis of the cytokine profile in the duodenal mucosa of refractory coeliac disease patients. (2014) Clin Sci (Lond) 126(6): 451-458.

55. Goodman, T., Lefrancois, L. Expression of the gamma-delta T-cell receptor on intestinal CD8+ intraepithelial lymphocytes. (1988) Nature 333(6176): 855-858.

56. Itohara, S., Farr, A.G., Lafaille, J.J., et al. Homing of a gamma delta thymocyte subset with homogeneous T-cell receptors to mucosal epithelia. (1990) Nature 343(6260): 754-757.

57. Hayday, A., Tigelaar, R. Immunoregulation in the tissues by gammadelta T cells. (2003) Nat Rev Immunol 3(3): 233-242.

58. Boismenu, R. Function of intestinal gammadelta T cells. (2000) Immunol Res 21(2-3): 123-127.

59. Komano, H., Fujiura, Y., Kawaguchi, M., et al. Homeostatic regulation of intestinal epithelia by intraepithelial gamma delta T cells. (1995) Proc Natl Acad Sci USA 92(13): 6147-6151.

60. Mak, T.W., Ferrick, D.A. The gammadelta T-cell bridge: linking innate and acquired immunity. (1998) Nat Med 4(7): 764-765.

61. Chen, Y., Chou, K., Fuchs, E., et al. Protection of the intestinal mucosa by intraepithelial gamma delta T cells. (2002) Proc Natl Acad Sci USA 99(22): 14338-14343.

62. Halstensen, T.S., Scott, H., Brandtzaeg, P. Intraepithelial T cells of the TcR gamma/delta + CD8- and V delta $1 / \mathrm{J}$ delta $1+$ phenotypes are increased in coeliac disease. (1989) Scand J Immunol 30(6): 665-672.

63. Spencer, J., Isaacson, P.G., MacDonald, T.T., et al. Gamma/delta $\mathrm{T}$ cells and the diagnosis of coeliac disease. (1991) Clin Exp Immunol 85(1): 109-113.

64. Rust, C., Kooy, Y., Peña, S., et al. Phenotypical and functional characterization of small intestinal TcR gamma delta $+\mathrm{T}$ cells in coeliac disease. (1992) Scand J Immunol 35(4): 459-468.

65. Savilahti, E., Arato, A., Verkasalo, M. Intestinal gamma/delta receptor-bearing $\mathrm{T}$ lymphocytes in celiac disease and inflammatory bowel diseases in children. Constant increase in celiac disease. (1990) Pediatr Res 28(6): 579-581.

66. Maki, M., Holm, K., Collin, P., et al. Increase in gamma/delta T cell receptor bearing lymphocytes in normal small bowel mucosa in latent coeliac disease. (1991) Gut 32(11): 1412-1414.

67. Kutlu, T., Brousse, N., Rambaud, C., et al. Numbers of T cell recep- tor (TCR) alpha beta+ but not of TcR gamma delta+ intraepithelial lymphocytes correlate with the grade of villous atrophy in coeliac patients on a long term normal diet. (1993) Gut 34(2): 208-214.

68. Holm, K., Mäki, M., Savilahti, E. et al. Intraepithelial gamma delta T-cell-receptor lymphocytes and genetic susceptibility to coeliac disease. (1992) Lancet 339(8808): 1500-1503.

69. Bhagat, G., Naiyer, A.J., Shah, J.G., et al. Small intestinal CD8+T$\mathrm{CR} \gamma \delta+\mathrm{NKG} 2 \mathrm{~A}+$ intraepithelial lymphocytes have attributes of regulatory cells in patients with celiac disease. (2008) J Clin Invest 118(1): 281-293.

70. Forsberg, G., Hernell, O., Hammarstrom, S. Concomitant increase of IL-10 and pro-inflammatory cytokines in intraepithelial lymphocyte subsets in celiac disease. (2007) Intl Immunology 19(8): 993-1001.

71. Meresse, B., Chen, Z., Ciszewski, C., et al. Coordinated induction by IL15 of a TCR-independent NKG2D signaling pathway converts CTL into lymphokine-activated killer cells in celiac disease. (2004) Immunity 21(3): 357-366.

72. Hüe, S., Mention, J.J., Monteiro, R.C., et al. A direct role for NKG2D/MICA interaction in villous atrophy during celiac disease. (2004) Immunity 21(3): 367-377.

73. Meresse, B., Curran, S.A., Ciszewski, C., et al. Reprogramming of CTLs into natural killer-like cells in celiac disease. (2006) J Exp Med 203(5): 1343-1355.

74. Grose, R.H., Thompson, F.M., Cummins, A.G. Deficiency of 6B11+ invariant NK T-cells in celiac disease. (2008) Dig Dis Sci 53(7): 18461851.

75. Frisullo, G., Nociti, V., Iorio, R., et al. Increased CD4+CD25+Foxp3 $+\mathrm{T}$ cells in peripheral blood of celiac disease patients: correlation with dietary treatment. (2009) Hum Immunol 70(6): 430-435.

76. Granzotto, M., dal Bo, S., Quaglia, S., et al. Regulatory T-cell function is impaired in celiac disease. (2009) Dig Dis Sci 54(7): 1513-1519. 77. Di Niro, R., Mesin, L., Zheng, N.Y., et al. High abundance of plasma cells secreting transglutaminase 2-specific IgA autoantibodies with limited somatic hypermutation in celiac disease intestinal lesions. (2012) Nat Med 18(3): 441-445.

78. Rostom, A., Dubé, C., Cranney, A., et al. The diagnostic accuracy of serologic tests for celiac disease: a systematic review. (2005) Gastroenterology 128(4 Suppl 1): S38-S46.

79. Ierardi, E., Losurdo, G., Piscitelli, D. Seronegative celiac disease: where is the specific setting? (2015) Gastroenterol Hepatol Bed Bench 8(2): 110-116.

80. Monteleone, I., Monteleone, G., Del Vecchio Blanco, G., et al. Regulation of the Thelper cell type 1 transcription factor T-bet in coeliac disease mucosa. (2004) Gut 53(8): 1090-1095.

81. Biancheri, P., Di Sabatino, A., Rescigno, M., et al. Abnormal thymic stromal lymphopoietin expression in the duodenal mucosa of patients with coeliac disease. (2015) Gut [In Press].

82. Penedo-Pita, M., Peteiro-Cartelle, J. Increased serum levels of interleukin-2 and soluble interleukin-2 receptor in celiac disease. (1991) J Pediatr Gastroenterol Nutr 12(1): 56-60.

83. Kapoor, A., Patwari, A.K., Kumar, P., et al. Serum soluble interleukin-2 receptor, interleukin- 6 and tumor necrosis factor alpha as markers of celiac disease activity. (2013) Indian J Pediatr 80(2): 108-113.

84. Crabtree, J.E., Heatley, R.V., Juby, L.D., et al. Serum interleukin-2-receptor in coeliac disease: response to treatment and gluten challenge. (1989) Clin Exp Immunol 77(3): 345-348.

85. Dinarello, C.A. Cytokines as endogenous pyrogens. (1999) J Infect Dis 179 (Suppl 2): 294-304.

86. Dema, B., Martínez, A., Fernández-Arquero, M., et al. The IL6$174 \mathrm{G} / \mathrm{C}$ polymorphism is associated with celiac disease susceptibility in girls. (2009) Hum Immunol 70(3): 191-194.

87. Hansson, T., Dannæus, A., Klareskog, L. Cytokine-producing cells in peripheral blood of children with coeliac disease secrete cytokines with a type 1 profile. (1999) Clin Exp Immunol 116(2): 246-250.

88. Przemioslo, R.T., Lundin, K.E., Sollid, L.M., et al. Histological changes in small bowel mucosa induced by gliadin sensitive T lymphocytes can be blocked by anti-interferon gamma antibody. (1995) Gut 
36(6): 874-879.

89. Mazzarella, G. Effector and suppressor T cells in celiac disease. (2015) World J Gastroenterol 21(24): 7349-7356.

90. Bayardo, M., Punzi, F., Bondar, C., et al. Transglutaminase 2 expression is enhanced synergistically by interferon- $\gamma$ and tumour necrosis factor- $\alpha$ in human small intestine. (2012) Clin Exp Immunol 168(1): 95-104.

91. Molberg, O., Mcadam, S.N., Körner, R., et al. Tissue transglutaminase selectively modifies gliadin peptides that are recognized by gut-derived T cells in celiac disease. (1998) Nat Med 4(6): 713-717.

92. Klemenak, M., Dolinšek, J., Langerholc, T., et al. Administration of Bifidobacterium breve Decreases the Production of TNF- $\alpha$ in Children with Celiac Disease. (2015) Dig Dis Sci 60(11): 3386-3392.

93. Wan, Y.Y., Flavell, R.A. How diverse- CD4 effector Tcells And their functions. (2009) J Mol Cell Biol 1(1): 20-36.

94. Björck, S., Lindehammer, S.R., Fex, M., et al. Serum cytokine pattern in young children with screening detected coeliac disease. (2015) Clin Exp Immunol 179(2): 230-235.

95. Eaton, A.D., Xu, D., Garside, P. Administration of exogenous interleukin-18 and interleukin-12 prevents the induction of oral tolerance. (2003) Immunology 108(2): 196-203.

96. Sato, N., Patel, H.J., Waldmann, T.A., et al. The IL-15/IL-15R alpha on cell surfaces enables sustained IL-15 activity and contributes to the long survival of CD8 memory T cells. (2007) Proc Natl Acad Sci USA 104(2): 588-593.

97. Dubsky, P., Saito, H., Leogier, M., et al. IL-15-induced human DC efficiently prime melanoma-specific naive $\mathrm{CD} 8+\mathrm{T}$ cells to differentiate into CTL. (2007) Eur J Immunol 37(6): 1678-1690.

98. Maiuri, L., Ciacci, C., Auricchio, S., et al. Interleukin 15 mediates epithelial changes in celiac disease. (2000) Gastroenterology 119(4): 996-1006.

99. Di Sabatino, A., Ciccocioppo, R., Cupelli, F., et al. Epithelium derived interleukin 15 regulates intraepithelial lymphocyte Th1 cytokine production, cytotoxicity, and survival in coeliac disease. (2006) Gut 55(4): 469-477.

100. Ebert, E.C. Interleukin 21 up-regulates perforin-mediated cytotoxic activity of human intra-epithelial lymphocytes. (2009) Immunology 127(2): 206-215.

101. Spolski, R., Leonard, W.J. Interleukin-21: basic biology and implications for cancer and autoimmunity. (2008) Annu Rev Immunol 26: 57-79.

102. McInnes, I.B., Gracie, J.A. Interleukin-15: a new cytokine target for the treatment of inflammatory diseases. (2004) Curr Opin Pharmacol 4(4): 392-397.

103. De Nitto, D., Monteleone, I., Franzè, E., et al. Involvement of interleukin-15 and interleukin-21, two gamma-chain-related cytokines, in celiac disease. (2009) World J Gastroenterol 15(37): 4609-4614.

104. Hmida, N.B., Ben Ahmed, M., Moussa, A., et al. Impaired control of effector T cells by regulatory T cells: a clue to loss of oral tolerance and autoimmunity in celiac disease? (2012) Am J Gastroenterol 107(4): 604-611.

105. Korneychuk, N., Ramiro-Puig, E., Ettersperger, J., et al. Interleukin 15 and CD4+ T cells cooperate to promote small intestinal enteropathy in response to dietary antigen. (2014) Gastroenterology 146(4): 1017-1027.

106. Harris, K.M., Fasano, A., Mann, D.L. Monocytes Differentiated with IL-15 Support Th17 and Th1 Responses to Wheat Gliadin: Implications for Celiac Disease. (2010) Clin Immunol 135(3): 430-439.

107. Bettelli, E., Oukka, M., Kuchroo, V.K. T(H)-17 cells in the circle of immunity and autoimmunity. (2007) Nat Immunol 8(4): 345-350.

108. Castellanos-Rubio, A., Santin, I., Irastorza, I., et al. TH17 (and TH1) signatures of intestinal biopsies of CD patients in response to gliadin. (2009) Autoimmunity 42(1): 69-73.
109. Gianfrani, C., Levings, M.K., Sartirana, C., et al. Gliadin-specific type 1 regulatory T cells from the intestinal mucosa of treated celiac patients inhibit pathogenic T cells. (2006) J Immunol 177(6): 4178-4186. 110. Salvati, V.M., Mazzarella, G., Gianfrani, C., et al. Recombinant human interleukin 10 suppresses gliadin dependent $\mathrm{T}$ cell activation in ex vivo cultured coeliac intestinal mucosa. (2005) Gut 54(1): 46-53.

111. Benahmed, M., Meresse, B., Arnulf, B., et al. Inhibition of TGF-beta signaling by IL-15: a new role for IL-15 in the loss of immune homeostasis in celiac disease. (2007) Gastroenterology 132(3): 994-1008. 112. Hansson, T., Ulfgren, A.K., Lindroos, E., et al. Transforming growth factor-beta (TGF-beta) and tissue transglutaminase expression in the small intestine in children with coeliac disease. (2002) Scand J Immunol 56(5): 530-537.

113. Lahat, N., Shapiro, S., Karban, A., et al. Cytokine profile in coeliac disease. (1999) Scand J Immunol 49(4): 441-446.

114. Yoshie, O., Imai, T., Nomiyama, H. Chemokines in immunity. (2001) Adv Immunol 78: 57-110.

115. Colvin, R.A., Campanella, G.S., Sun, J., et al. Intracellular domains of CXCR3 that mediate CXCL9, CXCL10, and CXCL11 function. (2004) J Biol Chem 279: 30219-30227.

116. Bonecchi, R., Bianchi, G., Bordignon, P.P., et al. Differential expression of chemokine receptors and chemotactic responsiveness of type $1 \mathrm{~T}$ helper cells (Th1s) and Th2s. (1998) J Exp Med 187(1): 129-134.

117. Poggi, A., Catellani, S., Fenoglio, D., et al. Adhesion molecules and kinases involved in $\gamma \delta \mathrm{T}$ cells migratory pathways: implications for viral and autoimmune diseases. (2007) Curr Med Chem 14(30): 3166-3170.

118. Katoh, S., Fukushima, K., Matsumoto, N., et al. Accumulation of CXCR3-expressing eosinophils and increased concentration of its ligands (IP10 and Mig) in bronchoalveolar lavage fluid of patients with chronic eosinophilic pneumonia. (2005) Int Arch Allergy Immunol 137(3): 229-235.

119. Johansson, C., Ahlstedt, I., Furubacka, S., et al. Differential expression of chemokine receptors on human $\operatorname{IgA}+$ and $\operatorname{IgG}+\mathrm{B}$ cells. (2005) Clin Exp Immunol 141(2): 279-287.

120. Kunkel, E.J., Butcher, E.C. Plasma-cell homing. (2003) Nat Rev Immunol 3(10): 822-829.

121. Penna, G., Vulcano, M., Sozzani, S., et al. Differential migration behavior and chemokine production by myeloid and plasmacytoid dendritic cells. (2002) Hum Immunol 63(12): 1164-1171.

122. Lammers, K.M., Lu, R., Brownley, J., et al. Gliadin induces an increase in intestinal permeability and zonulin release by binding to the chemokine receptor CXCR3. (2008) Gastroenterology 135(1): 194-104.

123. Lammers, K.M., Khandelwal, S., Chaudhry, F., et al. Identification of a novel immunomodulatory gliadin peptide that causes interleukin- 8 release in a chemokine receptor CXCR3-dependent manner only in patients with coeliac disease. (2011) Immunology 132(3): 432-440.

124. Lammers, K.M., Chieppa, M., Liu, L., et al. Gliadin Induces Neutrophil Migration via Engagement of the Formyl Peptide Receptor, FPR1. (2015) PLoS One 10(9): e0138338.

125. Marsh, M.N. Grains of truth: evolutionary changes in small intestinal mucosa in response to environmental antigen challenge. (1990) Gut 31(1): 111-114.

126. Oberhuber, G., Granditsch, G., Vogelsang, H. The histopathology of coeliac disease: time for a standardized report scheme for pathologists. (1999) Eur J Gastroenterol Hepatol 11(10):1185-1194.

127. Corazza, G.R., Villanacci, V., Zambelli, C., et al. Comparison of the interobserver reproducibility with different histologic criteria used in celiac disease. (2007) Clin Gastroenterol Hepatol 5(7): 838-843.
Ommega Publishers

Journal Title: Journal of Gastrointestinal Disorder \& Liver Function (JGDLF) Short name: J Gastro Dis Liver Func
ISSN No: 2471-0601

E-Mail Id: gastrology@ommegaonline.com

Website: www.ommegaonline.org 